\title{
An adding result in impression formation*
}

\author{
ANDREW M. LUGG \\ University of Michigan, Ann Arbor, Michigan 48104 \\ and \\ HARRY F. GOLLOB $\dagger$ \\ University of Denver, Denver, Colorado 80210
}

\begin{abstract}
Ss were presented with a highly polarized piece of information, followed by a same-signed moderately polarized piece of information, and were asked whether the second piece of information led them to like the person described more, less, or just the same. The obtained percentage of adding responses was $65 \%$; that is, most of the responses indicated that $\mathrm{Ss}^{\prime}$ impression of the person described became more polarized following addition of moderately polarized information $(p<.001)$. More adding was obtained for negatively than for positively evaluated adjectives $(\mathrm{p}<.05)$.
\end{abstract}

The purpose of the present study was to determine in a simple, direct fashion how the addition of moderately polarized stimulus information to highly polarized stimulus information of the same evaluative sign changes the polarity of Ss' reports of their subjective evaluations of a stimulus object.

Suppose, given that a trustworthy person is highly likable and a persuasive person is moderately likable, one wished to find out whether a trustworthy, persuasive person is more or less likable than a trustworthy person. One natural way to do this is as follows. Present Ss with the highly polarized piece of information, then with the same-signed moderately polarized piece of information, and ask whether the new information leads them to like the stimulus person more or less. The Ss need only tell the $\mathrm{E}$ whether they liked the person more, less, or just the same for him to be able to determine how the moderately polarized information modifies the highly polarized information. Using this method, we aimed to determine whether Ss report adding or averaging responses, i.e., whether they report that their subjective impressions of the compound stimulus are more or less polarized than their impressions of the most polarized component stimulus.

Investigators using stimuli drawn from Anderson's (1968a) list of highly favorable $(\mathrm{H})$, moderately favorable $\left(\mathrm{M}^{+}\right)$, moderately unfavorable $\left(\mathrm{M}^{-}\right)$, and highly unfavorable (L) adjectives have uniformly found that their data are dominated by averaging responses when moderately polarized adjectives are integrated with highly polarized adjectives (Anderson, 1965, 1968b; Anderson \& Alexander, 1971; Gollob \& Lugg, 1973). Whereas the present study used compound stimuli

*This study was supported by National Institute of Mental Health Grant No. 18177 . We thank Robert S. Wyer, Jr. and Norman H. Anderson for their helpful criticisms of an early draft of this paper.

† Requests for reprints should be sent to Harry F. Gollob, Department of Psychology, University of Denver, Denver, Colorado 80210. consisting of two-adjective sets, the studies just cited used four-adjective compound stimuli. Hendrick (1968), however, used positively evaluated two-adjective sets and still found averaging in three separate studies. Like the present study, Anderson and Alexander's study and a study by Manis, Gleason, and Dawes (1966) used ordinal methods of measurement and thereby avoided many problems associated with studies that employ the usual type of rating scale. Both studies obtained averaging results. It was hoped that our use of a different ordinal measurement technique would shed light on the adding-averaging problem.

Although some adding results have been reported (e.g., Fishbein \& Hunter, 1964; Hewitt, 1972; Rokeach \& Rothman, 1965), most impression formation studies have obtained averaging. Given the apparent robustness of the averaging phenomenon, one would expect Ss to report in our direct test that their subjective impressions of a compound stimulus were less polarized than their subjective impressions of the most polarized component stimulus. That is, one would expect to obtain averaging responses; one would expect our measurement technique and those of others to yield convergent results.

\section{METHOD}

\section{Overview}

All 24 Ss made judgments as to whether hearing that a person had a moderately liked (or a moderately disliked) trait in addition to a highly liked (or a highly disliked) trait increased or decreased their liking of the stimulus person. For half of the Ss the scale was presented in one direction and for the other half in the opposite direction. Six male and six female college students served as paid Ss within each of these two conditions. Finally, all Ss made dislike-like ratings of the component adjectives and completed a final questionnaire.

\section{Selection of Stimuli}

The stimuli were selected from Anderson's (1968a) four subranges of $\mathrm{H}, \mathrm{M}^{+}, \mathrm{M}^{-}$, and $\mathrm{L}$ personality trait words. About 12 of the 32 adjectives in each of Anderson's subranges were 
dropped because they have low "meaningfulness ratings," as defined by Anderson, or because they have an exceptionally large variance of likableness ratings across $S s$. About five adjectives were eliminated from each set because they seemed to us to refer to temporary rather than to stable traits. Finally, nine adjectives were selected randomly from the remaining words in each of the four subranges.

Forty-one $\mathrm{HM}^{+}$pairs (i.e.. pairs consisting of a highly liked trait and a moderately liked trait) were constructed in the following manner. All possible combinations of five randomly selected $\mathrm{H}$ words and of five randomly selected $\mathrm{M}^{+}$words yielded $25 \mathrm{HM}^{+}$pairs. The other $16 \mathrm{HM}^{+}$pairs were obtained by taking all combinations of the remaining four $\mathrm{H}$ words and four $\mathrm{M}^{+}$ words. Forty-one $\mathrm{LM}^{-}$pairs were constructed by use of a similar procedure.

To help prevent $S$ s from falling into a fixed answering pattern 83 different filler items of types $\mathrm{HL}, \mathrm{M} \mathrm{M}^{+}, \mathrm{LL}$, etc., were used. Subject to the restriction that no stimulus adjectives be repeated on a given page, five items were randomly ordered on each page. As a further control for possible order effects, pages were thoroughly shuffled within each questionnaire.

\section{Instructions to Ss}

Ss were told that all names used in the questionnaire referred to male college students. As part of an illustrative example, Ss were asked to consider a student named Bill as being generally reliable, honest, and a good judge of character. They were further asked to "imagine that you are present when Bill is discussing with a friend the characteristics of a student, say Joe, about whom you have no information [other than knowing that he's a student]. In the course of the discussion, Bill say's that Joe is plcasant." Ss were told that at a later point in the discussion, "Bill say's that Joe is reserved," and were asked to "consider whether this new information inclines you to like Joe more or less. That is, how does Bill's additional judgment modify the impressions of Joe that you formed on the basis of the first judgment given by Bill?" Finally. Ss were told that each item in the questionnaire should be thought of as a shorthand description of the situation just described. The above example is represented by the following item:

Sentence 1: Bill says that Joe is pleasant.

Sentence 2: Bill says that Joe is reserved.

After having read Sentence 2, do you like Joe: Much less Slightly less Just the same Slightly more

Much more (In the actual questionnaire, the five response alternatives were typed on a single line.)

On the items for which data were analyzed, the more polarized adjective was always presented first. A different pair of male names was used for every item in the questionnaire.

In order to control for one type of response bias, the scale was presented in the direction shown above for half the $S s$ and in the opposite direction (i.e., from "Much more" to "Much less") for the other half of the Ss.

\section{Likableness Ratings and Final Questionnaire}

At the end of the questionnaire, Ss rated the 36 crucial $\mathrm{H}, \mathrm{M}^{+}$. $\mathrm{M}^{-}$, and $\mathrm{L}$ words and several filler items on an 11-point scale ranging from dislike $(-5)$ to like $(+5)$. After completing the likableness ratings, Ss completed a final questionnaire in which they were asked to explain in as much detail as possible the factors involved in their judgments.

\section{RESULTS}

Following transformation of the ratings on our II-point dislike-like scale to make them comparable to
Anderson's (1968a) 7-point scale, which ranged from 0 ("least favorable or desirable") to 6 ("most favorable or desirable"), we obtained the following mean ratings: $\mathrm{H}=4.96, \quad \mathrm{M}^{+}=3.63, \quad \mathrm{M}^{-}=2.20, \quad \mathrm{~L}=1.02$, which compare well with the mean ratings given by Anderson's normative sample $\left(\mathrm{H}=5.17, \mathrm{M}^{+}=3.60, \mathrm{M}^{-}=2.35\right.$, $\mathrm{L}=.87$ ).

If, on an $\mathrm{HM}^{+}$pair, a $\mathrm{S}$ checked "slightly more" or "much more" when an $\mathrm{H}$ word was followed by an $\mathrm{M}^{+}$ word, we say that the $\mathrm{S}$ gave an adding response. Similarly, we say that a $S$ gave an adding response if, on an $\mathrm{LM}^{-}$pair, he checked "slightly less" or "much less" for an $\mathrm{L}$ word followed by an $\mathrm{M}^{-}$word. If $\mathrm{S}$ checked "just the same," the response was coded as a "no-change" response. An averaging response was scored whenever other alternatives were checked. Over all conditions, the mean percentages of adding responses, no-change responses, and averaging responses were $65 \%$, $22 \%$, and $13 \%$, respectively.

Since simple adding models predict that adding responses will occur and simple averaging models predict that either averaging or "no-change" responses will occur, we decided to focus our analyses on comparing the occurrence of adding responses with the occurrence of both averaging and "no-change" responses combined. The proportions of adding responses were analyzed by use of a three-way analysis of variance which treated sex and direction of scale as between-S variables and the evaluative distiriction between $\mathrm{HM}^{+}$and $\mathrm{LM}^{-}$pairs as a within- $S$ variable. The main effect due to sex was significant $(p<.01, F=8.84, d f=1 / 20)$, with the proportion of adding responses being .59 for males and .71 for females. The main effect due to the evaluative distinction between $\mathrm{LM}^{-}$and $\mathrm{HM}^{+}$stimuli was also significant $(p<.05, F=4.64, \mathrm{df}=1 / 20)$, with the proportion of summative responses being .89 for the negative stimuli and .77 for the positive stimuli. No other main effects or interactions were significant.

The overall adding effect in the present data is large. Of those responses which indicated that some change in impression occurred, $83 \%$ were adding responses and only $17 \%$ were averaging responses. This difference is highly significant $(p<.0001, F=258.03, d f=1 / 20)$. Moreover, all but one of our Ss gave more adding than averaging responses within both the $\mathrm{HM}^{+}$and the $\mathrm{LM}^{-}$ pairs.

A three-way analysis of variance indicated that the proportions of "no-change" responses were not significantly affected by main effects or interactions involving sex, direction of scale, or evaluation of trait pairs.

\section{DISCUSSION}

\section{The Adding Result}

Our adding result differs markedly from the averaging results reported by Anderson $(1965,1968 \mathrm{c})$, Hendrick 
(1968), and Gollob and Lugg (1973). So, we first consider the possibility that these results are due to some artifact in the study. Perhaps our Ss simply ignored the first sentence of an item and said they liked a person more whenever the second sentence contained a positive trait and less whenever the second sentence contained a negative trait. Of course, we cannot prove that $S$ s did not use such a strategy. On the basis of their responses to the final questionnaire, however, we can say that Ss describe their judgment process as having been quite complex. No $S$ described his performance on the questionnaire in a way which even remotely suggested that he had ignored the first sentence in making his judgments. Moreover, if one assumes that Ss looked only at the second sentence when making judgments, how could one account for the finding that adding occurred more often for $\mathrm{LM}^{-}$pairs than for $\mathrm{HM}^{+}$pairs? Why should people ignore the first word relatively more often for negative than for positive pairs? In sum, we consider it unlikely that our adding result is due to an artifact of the methodology we used.

It may be thought that our result is due to the particular stimuli we used. This, however, is unlikely in view of the following: Our words were selected from Anderson's list and were all within the appropriate ranges of Anderson's $\mathrm{H}, \mathrm{M}^{+}, \mathrm{M}^{-}$, and $\mathrm{L}$ categories; the obtained mean ratings compared well with Anderson's mean ratings (see beginning of the present paper's RESULTS section); several other authors have obtained averaging results in studies that used similarly selected groups of stimuli (e.g., Anderson, 1965, 1968b; Anderson \& Alexander, 1971; Hendrick, 1968).

How, then, might our adding result be accounted for? We tentatively suggest the following. In our experiment, we asked Ss to tell us how new pieces of information changed their initial impressions; essentially we asked, "Does the new information incline you to like the stimulus person more or less?" Thus, our Ss were asked to adopt a direct comparison focus, in which they judged whether they would like a person more if he were described by a single $\mathrm{H}$ trait or if he were described by the same $\mathrm{H}$ trait together with an $\mathrm{M}^{+}$trait. It does not seem implausible to suggest that, when a S's attention is focused on making such a direct comparison, he is more likely to implicitly reason in an "adding" way something like this: "The stimulus person is trustworthy and that's very favorable. He is also persuasive and that's favorable too. So my initially favorable impression of him is supported and further enhanced." That is, it may be that, when an $\mathbf{S}$ approaches an impression formation task with an explicit focus on making a direct comparison between a current impression and the impression that results when some new information is added, each positive piece of information (even only slightly positive information) is seen as providing a further basis for liking the stimulus person. The $\mathrm{S}$ might, thus, be expected to judge that each positive piece of information further enhances his impression of the stimulus person.
Our study can be profitably compared to a recent study by Hewitt (1972). Using adjectives drawn from Anderson's (1968a) list of $\mathrm{H}, \mathrm{M}^{+}, \mathrm{M}^{-}$, and $\mathrm{L}$ traits, Hewitt constructed 64 pairs of stimuli in which Person A was described by an $\mathrm{H}$ (or $\mathrm{L}$ ) trait and Person $\mathrm{B}$ was described by the same $\mathrm{H}$ (or $\mathrm{L}$ ) trait and an $\mathrm{M}^{+}$(or $\mathrm{M}$ ) trait. For the $\mathrm{H}$ vs $\mathrm{HM}^{+}$pairs, Ss were asked whether they would be most attracted to Person A or Person B, or whether they would be attracted equally to both. An analogous question was asked for the $\mathrm{L}_{\text {and }} \mathrm{LM}^{-}$pairs. Ss who perceived the $\mathrm{M}^{+}$traits as desirable reported greater liking for stimulus persons described by the $\mathrm{HM}^{+}$ combinations than for stimulus persons described by the $\mathrm{H}$ trait alone. An analogous adding result was obtained for Ss who perceived the $\mathrm{M}^{-}$traits as undesirable. Although the basic methodology used in the two studies differed considerably, both Hewitt's study and ours essentially involved asking $S s$ to make a direct comparison between an $\mathrm{H}$ (or $\mathrm{L}$ ) and an $\mathrm{HM}^{+}$(or $\mathrm{LM}^{-}$) stimulus person where the same $\mathrm{H}$ (or $\mathrm{L}$ ) trait was used in both descriptions. For this reason, we suggest that part of the explanation for Hewitt's adding results may lie in the fact that his study, like the present one, can be interpreted as having involved a direct comparison focus.

The averaging results reported in two papers (Anderson \& Alexander, 1971; Anderson, 1968b) may be thought to present a problem for our suggested explanation of Hewitt's and our own adding results. But, as we will now show, this is not the case. In both the Anderson and Alexander and the Anderson studies, stimuli were selected individually for each $S$ to insure that the $\mathrm{H}$ and $\mathrm{M}^{+}$words were perceived as desirable and that the $\mathrm{L}$ and $\mathrm{M}^{-}$words were perceived as undesirable by each $\mathrm{S}$. In Anderson and Alexander's choice test of the averaging hypothesis, Ss were asked whether they best liked a person described by an $\mathrm{H}(\mathrm{L})$ word or a person described by a different $\mathrm{H}(\mathrm{L})$ word and an $\mathrm{M}^{+}\left(\mathrm{M}^{-}\right)$word in combination. This study was similar to Hewitt's but did not involve a direct comparison focus between an $\mathrm{H}$ and an $\mathrm{HM}^{+}$( $\mathrm{L}$ and $\mathrm{LM}^{-}$) stimulus person in which the same $\mathrm{H}(\mathrm{L})$ trait was involved. Although Ss in Anderson's (1968b) serial presentation task were continuously revising their impressions of the stimulus person, a direct comparison focus does not seem to be involved, since Ss were told that "each response should be made on the basis of all the accumulated information [p. 356]." Ss were asked to rate the stimulus person after being given each new adjective; they were not asked to make a direct comparison, as was the case in the Hewitt study and in the present study.

It is obvious that our adding result can be accounted for by a variety of models which assume that responses are a weighted sum of scale values. Less obviously, our result can also be subsumed under an averaging model. Anderson (1971) has proposed that a rating given to a person described by a single trait $A, R_{A}$, is a weighted average of the scale value associated with the trait, $S_{A}$, and the scale value associated with an initial impression, $\mathrm{I}_{\mathrm{O}}$, that is 


$$
R_{A}=\left(w_{A} S_{A}+w_{0} I_{0}\right) /\left(w_{A}+w_{0}\right)
$$

where $w_{A}$ and $w_{0}$ are weights which represent the psychological importance of the information. Anderson's model expresses the compound response, $R_{A B}$, to stimulus words $A$ and $B$, taken together as

$$
R_{A B}=\left(w_{A} S_{A}+w_{B} S_{B}+w_{0} I_{0}\right) /\left(w_{A}+w_{B}+w_{0}\right)
$$

It is easy to show by example that adding results are compatible with Eq. 1 and 2. If $\mathrm{H}$ and $\mathrm{M}^{+}$refer to highly favorable and moderately favorable traits, respectively, and if, for example, $\mathrm{S}_{\mathrm{H}}=8.80, \mathrm{~S}_{\mathrm{M}^{+}}=6.45, \mathrm{I}_{\mathrm{O}}=0$, $\mathrm{w}_{\mathrm{H}}=\mathrm{w}_{\mathrm{M}^{+}}=40$, and $\mathrm{w}_{\mathrm{O}}=.31$, we have by Eq. 1 and 2, $\mathrm{R}_{\mathrm{HM}^{+}}=5.50, \mathrm{R}_{\mathrm{H}}=4.96$, and $\mathrm{R}_{\mathrm{M}^{+}}=3.63$. A similar result can be obtained for negatively evaluated stimuli. Thus, Anderson's averaging model can account for our adding result in at least a qualitative fashion.

It may be thought that the $13 \%$ averaging result obtained in our study discredits any adding model. ${ }^{2}$ Anderson has argued that the averaging results obtained by him and his associates (e.g., Anderson, 1965; Anderson \& Alexander, 1971) critically infirm adding formulations of the impression formation process. Actually, such results only infirm certain simple adding formulations, e.g., that of Fishbein and Hunter (1964). Other adding models can account for both adding and averaging responses, as can be easily verified in the case of the following simple adding model:

$$
R=\frac{v_{k}}{k} \sum_{i=1}^{k} s_{i}
$$

where $\mathbf{R}$ denotes the response to a $\mathrm{k}$-component stimulus, $v_{k}$ denotes a weight that is constant for all $\mathrm{k}$-component stimuli and is greater than 1 for all $k>1$, and $s_{i}$ denotes the scale value associated with the ith stimulus component. In the case of two positively evaluated adjectives $\mathrm{A}$ and $\mathrm{B}$, we have

$$
\begin{aligned}
& R_{A}=v_{1} s_{A} ; R_{B}=v_{1} s_{B} \\
& R_{A B}=\frac{v_{2}}{2}\left(s_{A}+s_{B}\right)
\end{aligned}
$$

Then, assuming $\mathrm{v}_{1}=1.0$ and $\mathrm{v}_{2}=1.6$, an averaging result is obtained when $R_{A}=20$ and $R_{B}=4\left(R_{A B}=19.2\right)$, while an adding result is obtained when $R_{A}=20$ and $R_{B}=6\left(R_{A B}=20.8\right)$. Thus, we conclude that the major qualitative characteristics of our results can be plausibly accounted for by an adding model, as well as by an averaging model.

\section{Effects of Sex and Stimulus Evaluation on Adding}

The sex main effect we obtained suggests that female college Ss give adding responses more frequently than do male Ss. Perhaps the fact that our stimulus persons were described as male college students, rather than simply as people, is relevant in accounting for this result. Relative to male Ss, female college student Ss may give moderately positive and moderately negative information greater weight in determining the likability of male college student stimulus persons. In any case, since it is unusual for sex differences in the relative amount of adding and averaging responses to be reported in studies of impression formation, the present results should be treated cautiously.

We are aware of three other studies (Feldman, 1962; Hewitt, 1972; Wyer, 1971) which have reported data suggesting that proportionally more of Ss' responses increase in polarity when the components of a multitrait description are negatively rather than positively evaluated. Anderson and Alexander (1971), however, have reported the opposite effect. Although we do not know how to account for Anderson and Alexander's contrary result, we think the effect we report is genuine because of its appearance in at least three previous studies.

Warr (1969) and Kaplan (1971) have presented data which strongly suggest that, on the average, positively evaluated trait words have a greater degree of mutual implication than do negatively evaluated trait words. Dustin and Baldwin (1966) and Wyer (1970) have presented data supporting the hypothesis that redundant sets of trait words are averaged relatively more than less redundant sets of words. They argue that the tendency to add is greater to the extent that the added information is not already implied by the original traits, that is, when the additional information is nonredundant. These arguments and data suggest that our finding of relatively less adding for positively evaluated than for negatively evaluated sets of trait words is due in part to there being a greater degree of mutual implication between positively evaluated trait words than between negatively evaluated trait words.

\section{Concluding Remarks}

We close with the observation that if, as suggested, our 'Ss gave adding 'responses because they adopted a direct comparison focus, an interesting problem arises. Do Ss merely believe that adding $\mathrm{M}^{+}$information to $\mathrm{H}$ information would incline them to like a stimulus person more, although their actual impression of the person described as having an $\mathrm{HM}^{+}$combination of traits is less favorable than their impression would be if the person were described by the $\mathrm{H}$ trait alone? Or, are Ss who adopt a direct comparison focus in fact inclined to like a stimulus person more when $\mathbf{M}^{+}$information is added to H information?

\section{REFERENCES}

Anderson, N. H. Averaging versus adding as a 
stimulus-combination rule in impression formation. Journal of Experimental Psychology, 1965, 70, 394-400.

Anderson, N. H. Likableness ratings of 555 personality-trait words. Journal of Personality \& Social Psychology, 1968a, 9, 272-279.

Anderson, N. H. Application of a linear-serial model to a personality-impression task using serial presentation. Journal of Personality \& Social Psychology, 1968b, 10, 354-362.

Anderson, N. H. Integration theory and attitude change. Psychological Review, 1971, 78, 171-206.

Anderson, N. H., \& Alexander, G. R. Choice test of the averaging hypothesis for information integration. Cognitive Psychology, 1971, 2, 313-324.

Dustin, D. S., \& Baldwin, P. M. Redundancy in impression formation. Journal of Personality \& Social Psychology, 1966, 3, 500-506.

Feldman, S. Evaluative ratings of adjective-adjective combinations predicted from ratings of their components. Unpublished doctoral dissertation, Yale University, 1962.

Fishbein, M., \& Hunter, R. Summation versus balance in attitude organization and change. Journal of Abnormal \& Social Psychology, 1964, 69, 505-510.

Gollob, H. F., \& Lugg, A. M. Effects of instructions and stimulus presentation on the occurrence of averaging responses in impression formation. Journal of Experimental Psychology, 1973, 98, 217-219.

Hendrick, C. A. Averaging versus summation in impression formation. Perceptual \& Motor Skills, 1968, 00, 1295-1302.

Hewitt, J. Integration of information about others. Psychological Reports, 1972, 30, 1007-1010.

Kaplan, M. F. The determination of trait redundancy in personality impression formation. Psychonomic Science, 1971, 23, 280-282.

Manis, M., Gleason, T. C., \& Dawes, R. M. The evaluation of complex social stimuli. Journal of Personality \& Social Psychology, 1966, 3, 404-419.

Rokeach, M., \& Rothman, G. The principle of belief congruence and the congruity principle as models of cognitive interaction. Psychological Review, 1965, 72, 128-142.

Warr, P. B. Pollyanna's personal judgments. Unpublished manuscript, 1969.

Wyer, R. S., Jr. Information redundancy, inconsistency, and novelty and their role in impression formation. Journal of Experimental Social Psychology, 1970, 6, 111-127.

Wyer, R. S., Jr. A test of combination rules in impression formation using nonmetric multidimensional scaling. Unpublished manuscript, 1971.

\section{NOTES}

1. In this and following examples, we talk only about positively evaluated information. Similar remarks apply for negatively evaluated information.

2 , Adding and averaging models differ in that adding models "impose no constraints on the weight parameters whereas averaging models require the weights to sum to one [Anderson, 1971,p. 181]."

(Received for publication January 22, 1973; revision received March 19,1973 .) 